\title{
Effects of lactic acid fermentation on sensory profile of orange fleshed sweet potato
}

\author{
Benard O. Oloo ${ }^{1}$, Shitandi Anakalo ${ }^{2,}$, Mahungu Symon ${ }^{1}$, Malinga Joyce Barasa ${ }^{3}$ \\ ${ }^{1}$ Department of Food Science and technology, Egerton University, Egerton, Kenya \\ ${ }^{2}$ Division of Research, Kisii University, Kisii, Kenya \\ ${ }^{3}$ Kenya Agricultural Research Institute, Njoro, Kenya
}

Email address:

ashitandi@kisiiuniversity.ac.ke(S. Anakalo)

To cite this article:

Benard O. Oloo, Shitandi Anakalo, Mahungu Symon, Malinga Joyce Barasa. Effects of Lactic Acid Fermentation on Sensory Profile of Orange Fleshed Sweet Potato. Journal of Food and Nutrition Sciences. Vol. 1, No. 1, 2013, pp. 13-17. doi: 10.11648/j.jfns.20130101.13

\begin{abstract}
Lacto-products processed by lactic acid fermentation are known to have nutraceutical attributes and create variety in the beverage composition. Due to their high nutritive value, they are beneficial to human health when consumed regularly. In this study orange fleshed potato varieties (Zapallo, Nyathiodiewo and SPK004/06) were fermented with Lactobacillus plantarum MTCC 1407 at $25 \pm 2{ }^{\circ} \mathrm{C}$ for $48 \mathrm{~h}$ and kept for 28 days to make lacto-pickles. An optimization of process conditions was done by varying brine levels with fermentation time. The fermented products were subjected to panelist evaluation for flavour profiling. The product sensory scores were (1.5-2.5) on a 5 point hedonic scale ranging from dislike slightly to like much. The product with brine levels at 4 and $6 \%$ were found to be most preferred. The findings from this study indicate the acceptability of the developed lacto-pickles and suggest that the development of new products from sweet potato with functional attributes could improve its consumption among families while enhancing the shelf life of the product. It was concluded that the $\beta$-carotene rich, sweet potato lacto-pickle is a novel product which could find wide acceptance with good prospects for commercialization in small-scale industries.
\end{abstract}

Kewords: Lactic Acid, Fermentation, Sensory, Orange Fleshed Potato

\section{Introduction}

Sweet potato is an important part of the staple diet of populations in tropical regions where it is grown up to an elevation of $2,000 \mathrm{~m}$ above sea level [1]. It is grown in abundance around major lakes in the East African Rift Valley of Uganda, Rwanda, Burundi, Tanzania and Kenya $[2,3]$. Sweet potatoe roots are rich in starch, sugar, vitamin $\mathrm{C}, \beta$-carotene, iron and minerals. Their leaves are high in essential amino acids lysine and tryptophan. These two amino acids are always limiting in cereals thus, the sweet potato leaves can easily complement cereal based diets in the region [2].

In Africa, Sweet potatoes are usually consumed without special processing. The fresh tubers are either, boiled, baked, roasted or fried. Sweet potato flour and starch may also be processed [1]. Utilizing new cultivars of OFSP that have the nutritious benefits and also containing pigments including; flavones, phenolic acids, and anthocyanins, is one way to expand the market opportunities for the sweet potato industry $[2,3,4]$. The development of new products from sweet potato with functional attributes could further improve its consumption among families while improving on the shelf life of the product [2, 3, 4]. Some varieties of sweet potatoes contain coloured pigments such as $\beta$ carotene, anthocyanin and phenolic compounds. These pigments form the basis of classifying the foods as nutraceuticals [5]. They are considered anti-oxidants having physiological attributes such as; anti-cancer, protection against night blindness, ageing, and liver injury [5]. Nutritionally, sweet potatoes usually have higher protein content than other tubers such as cassava and yams.

In this study orange fleshed potato varieties (Zapallo, Nyathiodiewo and SPK004/06) were fermented with Lactobacillus plantarum MTCC 1407 at $25 \pm 2{ }^{\circ} \mathrm{C}$ for $48 \mathrm{~h}$ and kept for 28 days to make lacto-pickles. An optimization of process conditions was done by varying brine levels with fermentation time. The new Lacto products from sweet potato had enhanced nutraceutical attributes and sensory (texture, taste, flavour and after taste) attributes of sweet potato lacto-juice were evaluated. 


\section{Methods}

The project was carried out at Egerton University, Kenya Agricultural Research Institute (KARI)-Njoro and Kenya Industrial Research Development Institute (KIRDI) Nairobi laboratories. Sweet potatoes of the varieties: SPK/004/6 and Zapallo and Nyathiodiewo were used for the experiment. The OFSP samples were collected randomly from KARI (Njoro in Kenya) demonstration plots during peak harvesting season. KARI-Njoro lies between $0^{\circ} 20^{\circ}$ South and $35^{\circ} 56^{\circ}$ East of Kenya. The area receives an average rainfall of $939 \mathrm{~mm}$ per annum, with mean temperature of $14.9^{\circ} \mathrm{C}$. The site is classified as lower highland 2 to 3 agro-ecological zones and has a sub humid modified tropical climate. The experiment was laid out in a completely Randomized Block Design. A ten day period was allowed to elapse before the second collection of replicate samples. Samples were packed in 10-kg colorcoded mesh bags, and transported to KARI laboratories. Once at the Laboratory, the sweet potatoes were kept at room temperature $\left(25 \pm 2^{\circ} \mathrm{C}\right)$ in a lockable compartment for use within 24 hours.

\subsection{Preparation of L. Plantarum (Mtcc 1407) Culture}

The L. plantarum (MTCC 1407) culture was procured from the Institute of Microbial Technology, India. The bacterial culture was grown on MRS Agar medium to test potency and then counted to determine the viable cells. The culture was kept at $30^{\circ} \mathrm{C}$ for 24 hours and then extended to 36 hours. To prepare inocula of LAB, an isolated colony of each strain was transferred from MRS agar into a test tube containing $10 \mathrm{~mL}$ of sterile MRS broth (Merck; Darmstadt, Germany), which were incubated overnight at $30^{\circ} \mathrm{C}$ to obtain a culture containing approximately $10^{6} \mathrm{cfu} \mathrm{mL}-1$. When necessary, the culture was diluted with MRS broth to obtain the required cell numbers. Stock cultures of LAB strains were maintained as frozen stocks at $-80^{\circ} \mathrm{C}$ in $20 \%$ (vol/vol) sterile glycerol (Merck; Darmstadt, Germany).

\subsection{Pickling of Sweet Potato}

The roots were prepared by hand washing, peeling and then cutting into small cubes (approximately $1 \mathrm{x} 1 \mathrm{~cm}$ ). The cubes were blanched at $70^{\circ} \mathrm{C}$ for $10 \mathrm{~min}$. One hundred and forty grams $(140 \mathrm{~g})$ of the blanched sweet potato cubes were dispensed in 500-mL plastic jars. A brine solution at five different concentrations $(2,4,6,8$ and $10 \%)$ was prepared by dissolving $(10 \mathrm{~g}, 20 \mathrm{~g}, 30 \mathrm{~g}, 40 \mathrm{~g}$ and $50 \mathrm{~g})$ of salt $(\mathrm{NaCl})$ in $500 \mathrm{ml}$ of distilled water. $300 \mathrm{~mL}$ of the prepared brine solution was then added to each bottle. $7 \mathrm{ml}$ of the starter culture $\left(1 \times 10^{7} \mathrm{cfu} / \mathrm{ml}\right)$ was inoculated into each bottle and then each bottle was capped tightly. One negative control sample (with no salt and no Lactobacillus plantarum) was maintained. The entries were randomized in three replications.

The sweet potato brine solutions mixture was fermented at $25 \pm 2{ }^{\circ} \mathrm{C}$ and the fermentation allowed to continue for 28 days for the pickle to season. A preservative, Potassium
Metabisulphite $(100 \mathrm{mg} / \mathrm{g})$ was added to prevent the growth of undesirable microorganisms such as the salttolerant fungi-Aspergillus species. The flow diagram for this process is shown in Figure 1.

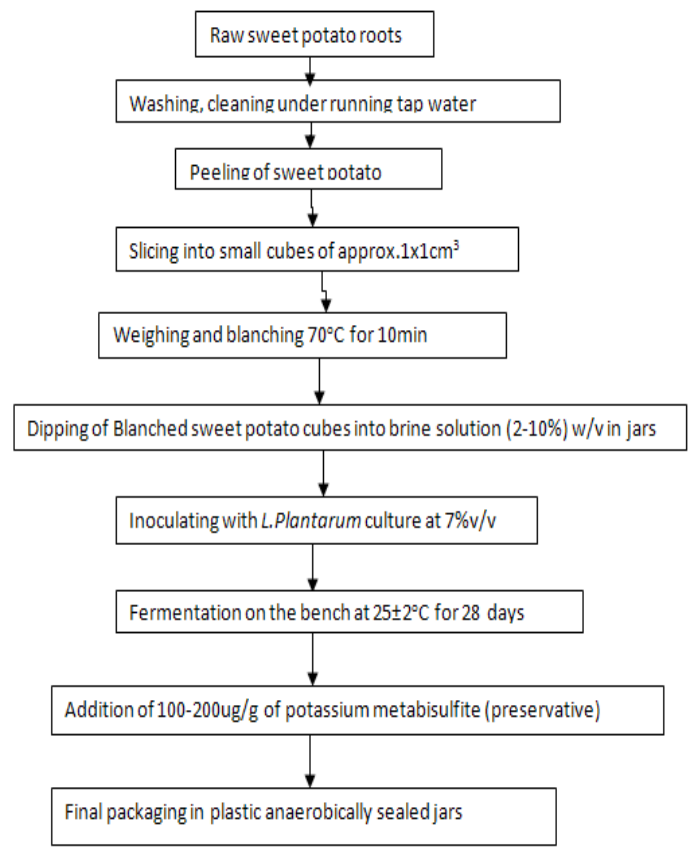

Figure 1. The flow diagram for the fermentation of Lacto-pickles.

\subsection{Sensory Evaluation and Flavor Profiling}

A semi-trained panel was involved in flavor profiling of the basic attributes of the product samples according to the method of Cross et al. [6]. The product was then subjected to affective sensory test according to the procedure below: Sensory attributes (taste, aroma, flavor, color/appearance and aftertaste) were evaluated using a 5-point hedonic scale (where $1=$ dislike extremely and $5=$ like extremely) by an 18 member panel (gender: 10 women, 8 men; age group: 20-40) selected from University staff Egerton University Njoro. The samples were served in polypropylene transparent cups, which had been labeled with a 3-digit random number. Questionnaires and water to rinse the mouth between each tasting sessions were provided. Panelists were advised to have at least 15 seconds break before tasting the next sample.

Prior to evaluation, a session was held to familiarize the panelists with the product. The panel was then asked to read through the questionnaires and understand the meaning of each attribute (texture, taste, aroma, flavor, color/appearance and aftertaste) to avoid any misinterpretation. The tasters were not allowed to discuss their findings with one another during the evaluation session. Another set of lacto-pickles were evaluated as replication the following day. Sensory evaluation data was presented as a mean of the 18 panelists' score. A standard ttest was used to test the statistical significance $(p<0.05)$ of the differences observed between the scores of the two tests. 


\subsection{Statistical Analysis}

Statistical analysis was performed by using the JMP Software version. One-way analysis of variance (ANOVA) and least significant difference (LSD) was used for statistical comparison. Differences were considered significant at the $\mathrm{P}<0.05$ level.

\subsection{Experimental Design}

The experimental design was the completely randomized design (CRD) and mean comparison using the least significant difference (LSD) procedure.

Model: $\mathrm{y}_{\mathrm{i}}=\mu+\tau_{\mathrm{i}}+\varepsilon_{\mathrm{ij}}$

$\mathrm{y}_{\mathrm{i}}=$ individual observation of the $\mathrm{i}^{\text {th }}$ treatment and the $\mathrm{j}^{\text {th }}$ replication

$\mu=$ is the overall mean.

$\tau_{\mathrm{i}}=$ the $\mathrm{i}^{\text {th }}$ treatment effect

$\varepsilon_{\mathrm{ij}}=$ the random error component

\section{Results and Discussion}

Table 1 provides an Analysis of variance for the sensory evaluation of the cooked OFSP varieties. The results indicate that the Zapallo variety outperformed the others in most of the parameters under investigation and giving highest scores on the general acceptability with a mean of 4.0. Coupled with the fact that it had the highest amount of $\beta$-carotene of $170.02 \mathrm{mg} / \mathrm{kg}$; this variety was selected for the following fermentation process steps.

Table 1. Analysis of variance for the sensory evaluation of the cooked OFSP varieties.

\begin{tabular}{lccc}
\hline \multicolumn{4}{c}{ Evaluation 1 } \\
\hline Sensory Quality & Zapallo & Nyathiodiewo & SPK004/06 \\
\hline Appearance & $3.9^{\mathrm{a}}$ & $3.6^{\mathrm{a}}$ & $2.5^{\mathrm{b}}$ \\
Taste & $3.9^{\mathrm{a}}$ & $3.5^{\mathrm{a}}$ & $2.7^{\mathrm{b}}$ \\
Flavour & $3.8^{\mathrm{a}}$ & $3.2^{\mathrm{b}}$ & $2.5^{\mathrm{c}}$ \\
Starchiness & $3.5^{\mathrm{a}}$ & $2.6^{\mathrm{b}}$ & $2.8^{\mathrm{b}}$ \\
Fibrousness & $3.2^{\mathrm{a}}$ & $3.6^{\mathrm{a}}$ & $3.3^{\mathrm{a}}$ \\
General & $4.0^{\mathrm{a}}$ & $3.5^{\mathrm{b}}$ & $2.7^{\mathrm{c}}$ \\
Acceptability & & & \\
\hline
\end{tabular}

Values are means of panelist's scores: 1=dislike extremely; 2=like moderately; $3=$ like much; $4=$ like very much; $5=$ like extremely. $*$ Means on the same row followed by the same letters are not significantly different according to least significant difference at $\mathrm{P} \leq 0.05$

From both figure 2 and table 2 it was observed that for flavor, the panelists' scores ranged from 2.3 to 1.5 , on a hedonic scale of 0 to 5 as explained above in the foot note. The results (Figure 2 and table 2) suggests that the consumer responses to the lacto--pickles under this study may have been greatly enhanced by incorporating some acceptable amount of sugar. Evidently, most panelists in their comments reacted to the high salt level which may have been masked by the sugar. Furthermore, the additional sugar would provide more substrate for $L$. plantarum metabolism leading to a product of more physiological and microbial integrity.

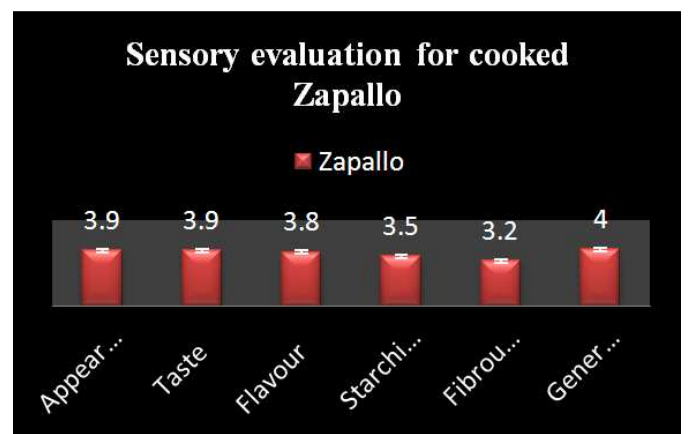

Figure 2. The Effects of fermentation on the Sensory profile and consumer acceptability.

Table 2. The panel test results for the fermented samples.

\begin{tabular}{lcccccc}
\hline & $\mathbf{0 \%}$ & $\mathbf{2 \%}$ & $\mathbf{4 \%}$ & $\mathbf{6 \%}$ & $\mathbf{8 \%}$ & $\mathbf{1 0 \%}$ \\
\hline Flavor & $2.14^{\mathrm{ab}}$ & $2.14^{\mathrm{ab}}$ & $2.3^{\mathrm{a}}$ & $2.3^{\mathrm{a}}$ & $1.93^{\mathrm{ab}}$ & $1.5^{\mathrm{c}}$ \\
Taste & $2.5^{\mathrm{a}}$ & $2.6^{\mathrm{a}}$ & $2.6^{\mathrm{a}}$ & $2.7^{\mathrm{a}}$ & $2.3^{\mathrm{a}}$ & $2.5 \mathrm{a}$ \\
General Appearance & $2.5^{\mathrm{a}}$ & $2.5^{\mathrm{a}}$ & $2.2^{\mathrm{a}}$ & $2.14^{\mathrm{a}}$ & $2.0^{\mathrm{a}}$ & $2.3 \mathrm{a}$ \\
\hline
\end{tabular}

*Means on the same row followed by the same letters are not significantly different according to least significant difference at $\mathrm{P} \leq 0.05$. Values are means of panelist's scores: $1=$ dislike extremely; $2=$ like moderately; $3=$ like much; 4=like very much; 5=like extremely.*Means on the same row followed by the same letters are not significantly different according to least significant difference at $\mathrm{P} \leq 0.05$

Sensory evaluation is a unique discipline that makes use of experimental design and statistical analysis concepts to human senses with the aim of evaluating consumer products [7]. The main tool for sensory analysis is often descriptive based on a given scale and in every situation either the panelists are trained on the experiences of a particular attribute or they may not be specifically trained [7]. The latter is especially used where a manufacturer is only interested in whether or not their product is acceptable to their target consumer. These subjective attributes are therefore used to discriminate and distinguish products based on: aroma, flavor, texture, after taste and sound properties.

Sensory evaluation may also perform other functions such as, quality control, tracking of quality changes in a product on storage and for investigation of general consumer perception of a product. The resulting data helps rate products based on the chosen attributes. Correlation analysis as well as the Principal Component Analysis, (PCA) have been used to measure linear variations between sample variables and reduce a large number of variables to two or three principal components respectively. The Sensory analysis therefore showed the panelists score their acceptability and preference on the various selected attributes; after taste, appearance and flavour.

From Figure 3 and 4 it was observed that the panelists responded with a preference for the $4 \%$ and six percent on both taste and flavour. It was further evident that increasing amount of salt beyond $6 \%$ was not agreeable to most panelists (Figure 3 and 4 ). The $8 \%$ and $10 \%$ fermented samples reported the lowest scores on flavor (Figure 3). Regarding taste, the most preferred was also the one with $6 \%$ 
salt followed by $4 \%$ and then $2 \%$ (Figure 4 ). There was however no significant difference in the test scores on taste at $0.05 \%$ level of significance. The profile for general appearance as observed in figure 5, showed no significant $(p<0.05 \%)$ difference in their preference for the appearance of the various sweet potato samples processed by lactic acid fermentation. The control received highest scores for appearance though, followed by $2 \%$ and the $10 \%$ brine processed lacto-pickle. This may be explained by the fact that these experienced the lowest degradation or fermentation as suggested by low level of acidity and higher accompanying $\mathrm{pH}$ value.

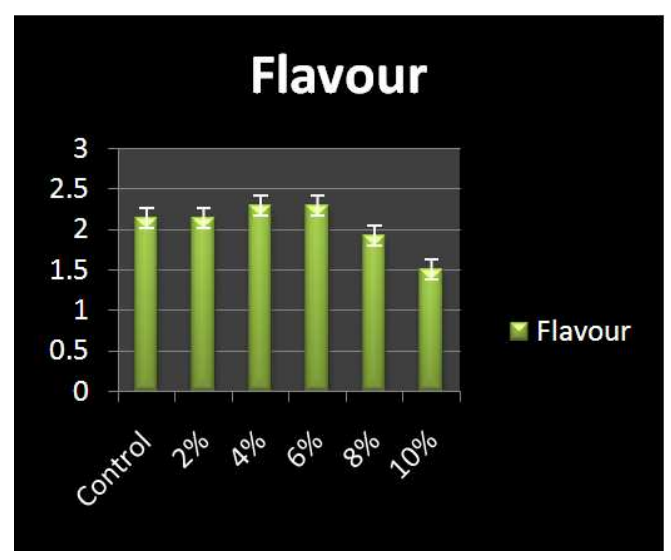

Figure 3. Panelists' response for flavour.

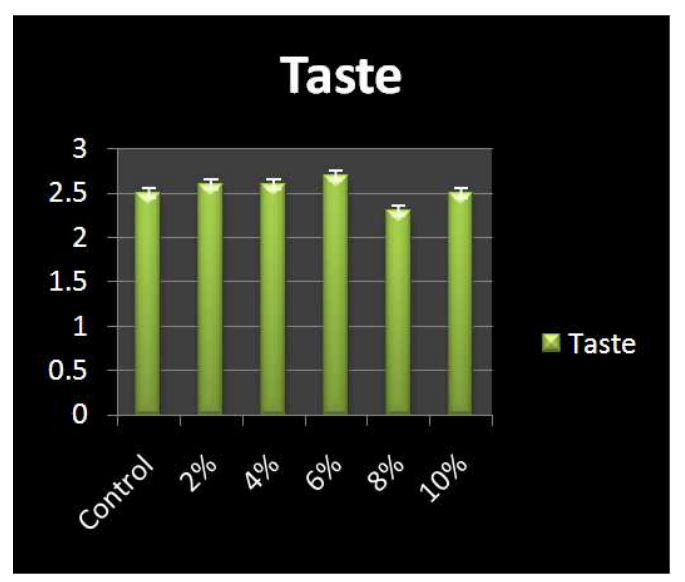

Figure 4. Panelists' response for Taste.

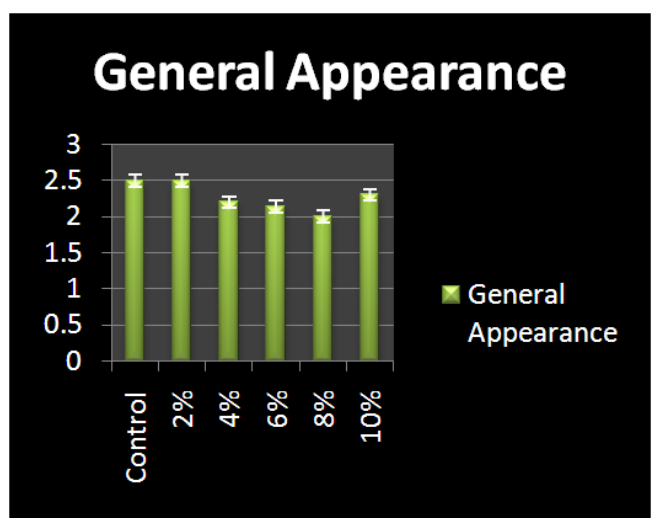

Figure 5. Panelists' response for General Appearance.
There was a general comment by consumers with regard to amount of salt as many respondents commented on the salt content. The concern for the high salt content could result in a lower appreciation of the product. This however provides an avenue for improving the product by adding sugar. Addition of sucrose could influence the consumer responses positively. This approach would be double prong. First it will avail more substrate for the action of Lactobacillus plantarum. Second, it would lead to a quicker rise in the LA content and finally, the sweetness would increase consumer acceptability. It would be of future interest to determine the exact percentage of sucrose which could be added for enhanced acceptability.

\section{Conclusion}

The findings from this study indicate the acceptability of the developed lacto-pickles. The development of new products from sweet potato with functional attributes will improve its consumption among families while improving on the shelf life of the product. The developed lacto-pickles will also find wider acceptance with good prospects for commercialization in small-scale industries. The $\beta$-carotene rich, sweet potato lacto-pickle would be a novel product similar to lactic acid-fermented cucumber, garlic and cabbage. Its regular consumption could be helpful in combating VAD related conditions such as; night blindness, liver injury, aging, and related ailments because of its antioxidant properties. It would also add value to the produce, and therefore increase revenue for farmers and processors.

\section{Acknowledgments}

The authors are grateful to the National Council for Science and Technology (NCST) for financial support through a research grant. We also thank Kenya Industrial Research Development Institute, Kenya Agricultural Research Institute and Egerton University Department of Food Science for kindly availing their laboratory facilities.

\section{References}

[1] Owori, C. B.; Lemaga, R.O.M.; Mwanga, R.; Namutebi, A ; Kapinga, R. (2007). Sweetpotato recipe book: sweetpotato processed products from Eastern and Central Africa. African Crop Science Society, Kampala, Uganda. 93pp.

[2] Kapinga R. Andrade, M. Lemaga, B., Amanada Gani, Crissman.C. and Wwanga.R. (2005). Role of Orange fleshed sweet potatoes in disaster mitigation: Experiences from East and Southern Africa. Africa crop science conference proceedings (7). 321-1329

[3] Ndolo P.J.1, Nungo R.A.1, Kapinga R.E.and Agili S. (2007). Development and promotion of orange-fleshed sweetpotato varieties in Western Kenya In the Proceedings of the 13th ISTRC Symposium, 2007pp. 689-695

[4] Mwanri, A. W., Kogi-Makau, W., and Laswail, H.S., (2011). Nutrients and antinutrients composition of raw, cooked and 
sun- dried sweet potato leaves. African Journal of Food Agriculture, Nutrition and Development. (11):5

[5] Ray, R.C., and Ward, O.P., (2006). Post-harvest microbial biotechnology of tropical root and tuber crops. In Microbial Biotechnology in Horticulture, Vol 1 (R.C. Ray and O.P.Ward, eds.) 345-395, Science Publishers Inc., Enfield, $\mathrm{NH}$.
[6] Cross, H.R.; Moen, R. and Stanfield, M.S. (1978). Training and testing of judges for sensory analysis of meat quality. Food Technol., 32(7), 48-54.

[7] Ranganna, S., (2001). Proximate Analysis, Color Measurement and Sensory Evaluation. Tata McGraw Hill Co. Ltd., New Delhi, India. 